\title{
Body temperature and above-ground patterns during hibernation in European hamsters (Cricetus cricetus L.)
}

\author{
Thomas Wassmer* \\ Department of Biology, University of Konstanz, P.O. Box 5560 M618, D-78434 Konstanz, Germany \\ (Accepted 3 September 2003)
}

\begin{abstract}
The purpose of this study was to determine whether hibernating European hamsters Cricetus cricetus, L., 1758 stay in their burrows all winter or if they occasionally spent time above ground. If 'time (spent) above ground' (TAG) occurred regularly throughout hibernation, the second objective of this work was to categorize and quantify the patterns of TAG during winter. For this purpose, 11 European hamsters were individually housed in wire mesh cages that were buried in the ground of an outdoor enclosure. Each cage was filled with soil up to ground level allowing the animals to construct their own burrows within the cages. Antennae in the bottom and top of the cage were calibrated to receive signals only when the hamsters were in their burrows or above the ground, respectively. This method enabled continuous recordings of the animal's TAG and provided ecologically meaningful results as the animals were housed in a way that closely resembled their natural habitat. About half of the hamsters stayed continuously below ground. Of these hamsters, almost all showed a dense pattern of episodes of reduced body temperature separated by only brief periods of normothermia. In contrast, the other half of the animals moved either episodically or even regularly above ground. For all of these hamsters, TAG was significantly reduced as compared to normothermic values. One hamster did not show any hibernation but did have a significantly reduced normothermic body temperature and did not leave its burrow for periods of up to 3 weeks.
\end{abstract}

Key words: Cricetus cricetus, hibernation, burrow, temperature, thermo-sensitive transmitter, time spent above ground

\section{INTRODUCTION}

At about the same size of a guinea pig, the European, black-bellied or common hamster Cricetus cricetus, L., 1758 is the largest European cricetid (averages for male hamsters: head and body $247 \mathrm{~mm}$, mass $385 \mathrm{~g}$ ). Hamsters transport their food, consisting of greens, seeds and tubers, in characteristic cheek (buccal) pouches and hoard them in their burrows. They live solitarily in a widespread burrow system containing storage and housing units and several exits. European hamsters inhabit the entire temperate Western Palaearctic (Eurasian) region (between $44-59^{\circ} \mathrm{N}$ and 5-95 E; Petzsch, 1952; Nechay, Hamar \& Grulich, 1977; Niethammer, 1982).

Similarly to most medium-sized homoiothermic animals living in higher latitudes, hibernation is the most efficient method for the European hamster to reduce energetic costs during the cold season (Heldmaier, Klaus \& Wiesinger, 1990).

In addition to the reduction of normal body temperature $\left(T_{\mathrm{b}}\right)$, hibernators were believed to stay in their shelters

*All correspondence to present address: Institut für Physiologische Chemie, Universität Mainz, D-55099 Mainz, Germany. E-mail: tom@wassmer.org until the end of winter. Until recently, owing to technical difficulties investigating this aspect of hibernation in nature, there were only anecdotal reports concerning time spent above ground (TAG) for hibernators during winter (Sulzer, 1774; Dubois, 1896; Eisentraut, 1928; Petzsch, 1936; Grulich, 1986). Although sophisticated technology such as radio-telemetry has been available since the 1960s, only a few investigations touched on this important aspect of hibernation. Vogel \& Frey (1995) and Vogel (1997) reported that two Gliridae species changed their hibernacula during winter. Körtner \& Geiser (1998) reported that a marsupial hibernator left its hibernacula after $67 \%$ of all temporary returns to normothermic $T_{\mathrm{b}}$ (interbout normothermia, IBN). Although it is much easier to access information on the activities of a hibernator during IBN in the laboratory, there is only a single study focused on this aspect. Torke \& Twente (1977) studied the time budget spent on different activities during IBN by the ground squirrel Spermophilus lateralis using visual observation. Mean duration of IBN was only 10.5 h, 93.4\% of which the animals spent motionless in their typical hibernation posture inside their hibernacula. Less than $7 \%$ of the time was used for any major locomotor activity and most of this was spent on the arrangement of bedding material 
Table 1. Time above-ground (TAG) data of 11 complete recordings for Cricetus cricetus used in this study. F, female; M, male; piNt, postimmergence normothermia; peNt, pre-emergence normothermia; TAG \% of IBN, TAG in \% of inter-bout normothermia; post HB TAG $(\%), \%$ of hibernation bouts followed by TAG. Values in parentheses are estimates in hamsters not showing all definition characteristics. N/A, not applicable: hamster 28 did not show any torpor bouts and therefore many variables could not be measured.

\begin{tabular}{|c|c|c|c|c|c|c|c|c|c|c|c|}
\hline Hamster & Sex & $\begin{array}{l}\text { Body } \\
\text { weight (g) }\end{array}$ & $\begin{array}{l}\text { Hibernation } \\
\text { (days) }\end{array}$ & $\begin{array}{l}\text { Heterothermia } \\
\text { (days) }\end{array}$ & $\begin{array}{l}\text { piNt } \\
\text { (days) }\end{array}$ & $\begin{array}{l}\text { peNt } \\
\text { (days) }\end{array}$ & $\begin{array}{l}\text { Total } \\
\text { TAG (h) }\end{array}$ & $\begin{array}{l}\text { Median TAG } \\
\text { duration } \pm 25 \text { th } \\
\text { percentile }(\mathrm{min})\end{array}$ & $\begin{array}{l}\text { TAG \% } \\
\text { of IBN }\end{array}$ & $\begin{array}{l}\text { Post HB } \\
\text { TAG (\%) }\end{array}$ & $\begin{array}{l}\text { Pattern } \\
\text { type }\end{array}$ \\
\hline 12 & M & 409 & 104.64 & 87.29 & 15.02 & 2.33 & 0.00 & - & 0.00 & 0.00 & 1 \\
\hline 13 & $\mathrm{~F}$ & 348 & 31.30 & 29.17 & 1.40 & 0.73 & 0.98 & $6.88 \pm 2.88$ & 0.32 & 57.14 & 2 \\
\hline 17 & $\mathrm{~F}$ & 370 & 195.85 & 166.97 & 28.09 & 0.80 & 0.00 & - & 0.00 & 0.00 & 1 \\
\hline 18 & $\mathrm{~F}$ & 330 & 140.84 & 123.14 & 17.11 & 0.58 & 2.04 & $15.31 \pm 7.43$ & 0.08 & 38.46 & 2 \\
\hline 20 & M & 498 & 168.72 & 160.83 & 7.40 & 0.49 & 0.00 & 0.00 & 0.00 & 0.00 & 1 \\
\hline 21 & M & 470 & 179.49 & 174.63 & 4.45 & 0.42 & 0.00 & 0.00 & 0.00 & 0.00 & 1 \\
\hline 23 & $\mathrm{~F}$ & 312 & $(158.27)$ & $(83.68)$ & $(73.57)$ & 1.02 & 16.05 & $11.15 \pm 3.55$ & 0.81 & 100.00 & 3 \\
\hline 25 & M & 456 & 144.65 & 118.26 & 25.88 & 0.51 & 7.15 & $15.75 \pm 13.15$ & 0.51 & 11.11 & 2 \\
\hline 26 & M & 410 & 143.09 & 119.28 & 11.15 & 12.65 & 1.00 & $4.63 \pm 1.08$ & 0.07 & 14.81 & 2 \\
\hline 27 & $\mathrm{~F}$ & 356 & 166.56 & 139.00 & 23.25 & 4.32 & 0.00 & 0.00 & 0.00 & 0.00 & 1 \\
\hline 28 & $\mathrm{~F}$ & 346 & (100.99) & N/A & N/A & N/A & 13.34 & $21.90 \pm 5.25$ & N/A & N/A & 4 \\
\hline
\end{tabular}

and grooming. Exploratory behaviour and feeding, which might involve leaving the hibernacula, accounted for $<1.5 \%$ of the time. However, the authors did not include periods of IBN $>15 \mathrm{~h}$, as they interpreted them as artefacts. These findings are supported by all studies on Spermophilus species in nature so far, as none of them report any TAG of the animals during winter (Young, 1990; Michener, 1992; Hut, van Oort \& Daan, 1999; Hut, Barnes $\&$ Daan, 2002). Even in these well-documented species, information about TAG during winter is exclusively based on observational data and discontinuous telemetry recordings.

The results of this study present continuous recordings of the location of European hamsters during hibernation along with continuous recordings of $T_{\mathrm{b}}$ in a high temporal resolution. The results presented below complement our present knowledge about hibernation patterns, which is solely based on changes in $T_{\mathrm{b}}$ (Young, 1990; Michener, 1992; Wollnik \& Schmidt, 1995; Wassmer, 1998; Hut, Barnes et al., 2002). Knowledge of TAG patterns is of crucial importance in defining the ambient climate and light conditions that the hibernators were subjected to in every recording period. This is important information, especially in studies focusing on the rhythmicity and energetics of hibernation. Finally, both variables, changes in $T_{\mathrm{b}}$ and TAG were used before to define the period of hibernation (cf. Cabanac \& Simon, 1987; Michener, 1992). Comparing both patterns should provide justification for these definitions or advice on other parameters to be taken into account, leading to a more open definition of hibernation.

\section{METHODS}

\section{Animals, housing and husbandry}

All 11 (5 male, 6 females) European hamsters used in this study were obtained from a free-range population near Strasbourg (France) in late May. According to their size and body weight (Vohralik, 1975), all hamsters were adults entering their second or third year (Table 1). Before the beginning of the experiments, the animals were kept in polyethylene laboratory cages $(0.55 \times 0.35 \times 0.2 \mathrm{~m})$ under standard laboratory conditions (light-dark cycle (LD) 16:8; ambient temperature $\left.\left(T_{\mathrm{a}}\right): 20 \pm 1{ }^{\circ} \mathrm{C}\right)$. Between September and October, the hamsters were transferred into an outdoor enclosure, where they were individually housed in wire mesh cages of $0.8 \times 0.8 \times$ $1.1 \mathrm{~m}$. Cages were buried $0.6 \mathrm{~m}$ into the ground and filled with soil up to the level of the surrounding ground. This depth corresponds well with values from the wild (Eisentraut, 1928) and allowed the hamsters to dig their own burrows inside the cages.

A mixture of wheat and corn grains (1:1) from a feeding rack and water from a bottle holder were provided ad libitum. Depending on the season, the diet was supplemented once a week by apples, carrots, herbs (clover, dandelion and various plantain species) and occasionally animal food, such as mealworms, earthworms and snails. Dry hay was provided as nesting material and added from time to time. After sufficient provisioning, feeding in the wintertime was limited to longer normothermic phases of the animals accompanied with TAG in order to avoid disturbances of the hibernation patterns.

\section{Surgery and telemetry}

Transmitters were implanted into the peritoneal cavity of each hamster anaesthetized by intraperitoneal injections of $50 \mathrm{mg}$ Ketamine (Kemint, Alvetra $\mathrm{GmbH}$, Neumünster, Germany) and $10 \mathrm{mg}$ Rompun (Bayer, Leverkusen, Germany) per kg body weight. For a post-surgery period of 10-14 days the animals were housed under the laboratory conditions described above and their health state regularly monitored. Fully recovered animals were transferred to the experimental enclosures. No increased morbidity, mortality or other problems resulted from the long-term use of intraperitoneal transmitters. 


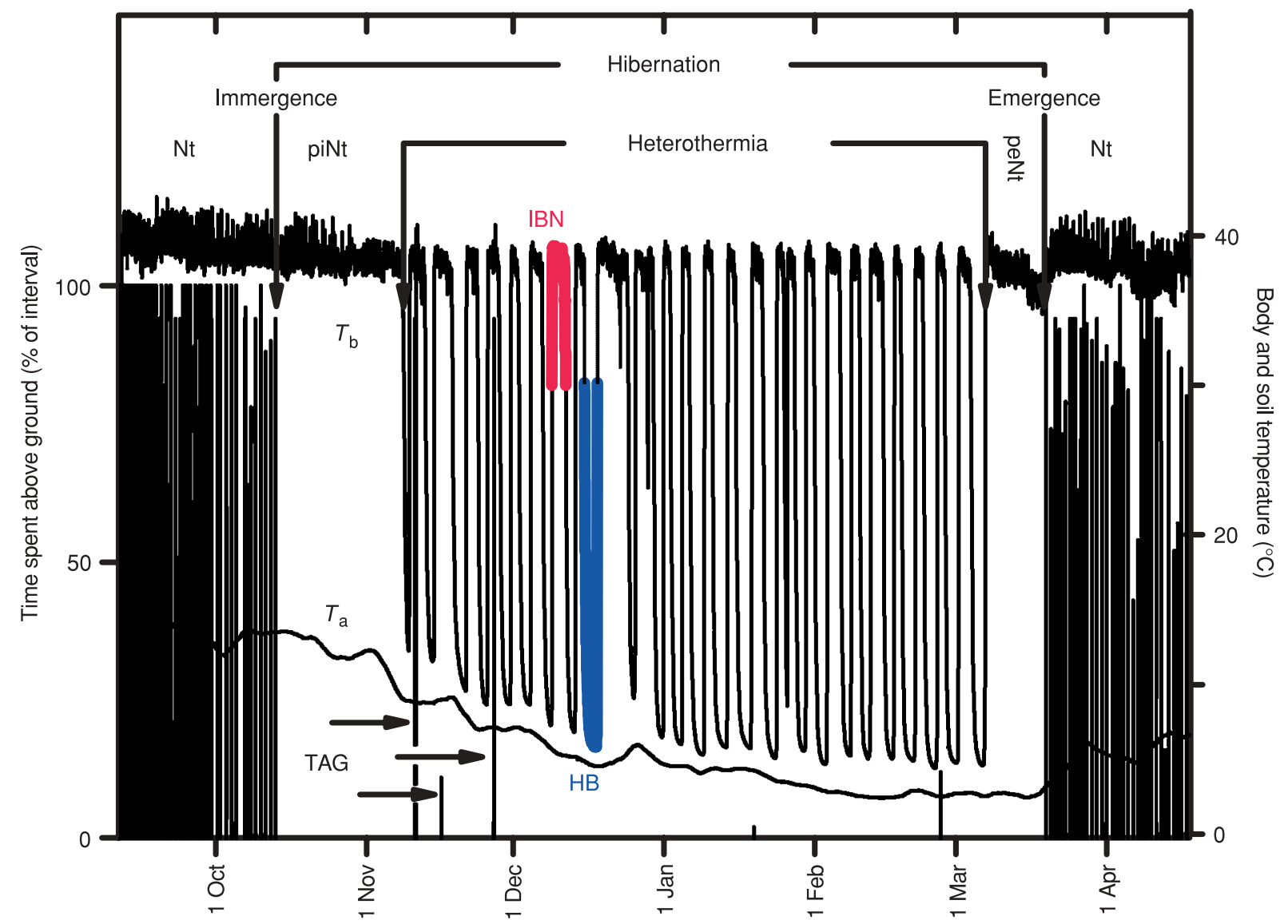

Fig. 1. Components of a hibernation pattern defined by the time-course of body temperature $\left(T_{\mathrm{b}}\right.$, upper line graph), soil temperature $\left(T_{\mathrm{a}}\right.$, lower line graph) and time spent above-ground (TAG, columns). For both line graphs, use right ordinate; For columns, use left ordinate, unit: percentage of a 5 min recording interval spent above ground.

The thermo-sensitive HF-transmitters used were developed by the Technical Workshop of the University of Konstanz. They were cylindrical, maximum dimensions 1.8 (diameter) $\times 4.2$ (height) $\mathrm{cm}$ and maximum weight $18.6 \mathrm{~g}$, corresponding to $\sim 5 \%$ of the body weight of a medium-sized European hamster. The dimensions and weight were mainly owing to the relatively large batteries producing a $3 \mathrm{~V}$ output at $950 \mathrm{mAh}$. Transmitters were coated with a mixture of beeswax and paraffin, suitable for implantation into the abdominal cavity of the hamsters.

All transmitters used the same optimized carrier frequency of $14 \mathrm{MHz}$. They were screened from each other by the metal cages. Another transmitter was buried into the soil at about the same depth as the bottom of the cages $(0.6 \mathrm{~m})$ and used as a reference for soil or insideburrow temperature. Each cage was equipped with 2 spiral antennae fixed into plastic platforms at the bottom and top of the cage. To achieve simultaneous recordings and to minimize the distance between transmitter and receiver, every cage was equipped with its own single super-heterodyne receiver.

The recording interval and sensitivity of the receivers were controlled by a personal computer containing a microcontroller card and running on a specially developed MS-DOS program that processed and stored the data. If the active antenna failed to receive a signal for $2 \mathrm{~s}$, the microcontroller triggered a switch to the other antenna.
This procedure continued, using geometrically increased sample periods up to a maximum of $32 \mathrm{~s}$, until a signal could be received by either antenna. Incoming data could be viewed on the PC screen and were stored on the hard disk as well as on a floppy disk.

\section{Recording of temperature and localization}

Temperature encoding pulse frequencies were converted into digital signals and passed on as disturbance-free optocoupled signals. All transmitters were simultaneously measured as moving averages over 32 values and saved at the end of the recording interval (usually set to $5 \mathrm{~min}$ ). To eliminate recording artefacts, the moving average procedure required at least 6 values with a maximum deviation of $<0.5 \%$. If incoming values failed this criterion, the last valid recording was kept until the criterion was met.

TAG was recorded as the percentage of an interval during which signals were received by the top antenna.

\section{Definition of events and time periods in hibernation}

In this study, hibernation patterns were defined by the time-course of $T_{\mathrm{b}}$ and TAG (Fig. 1). Before the onset 

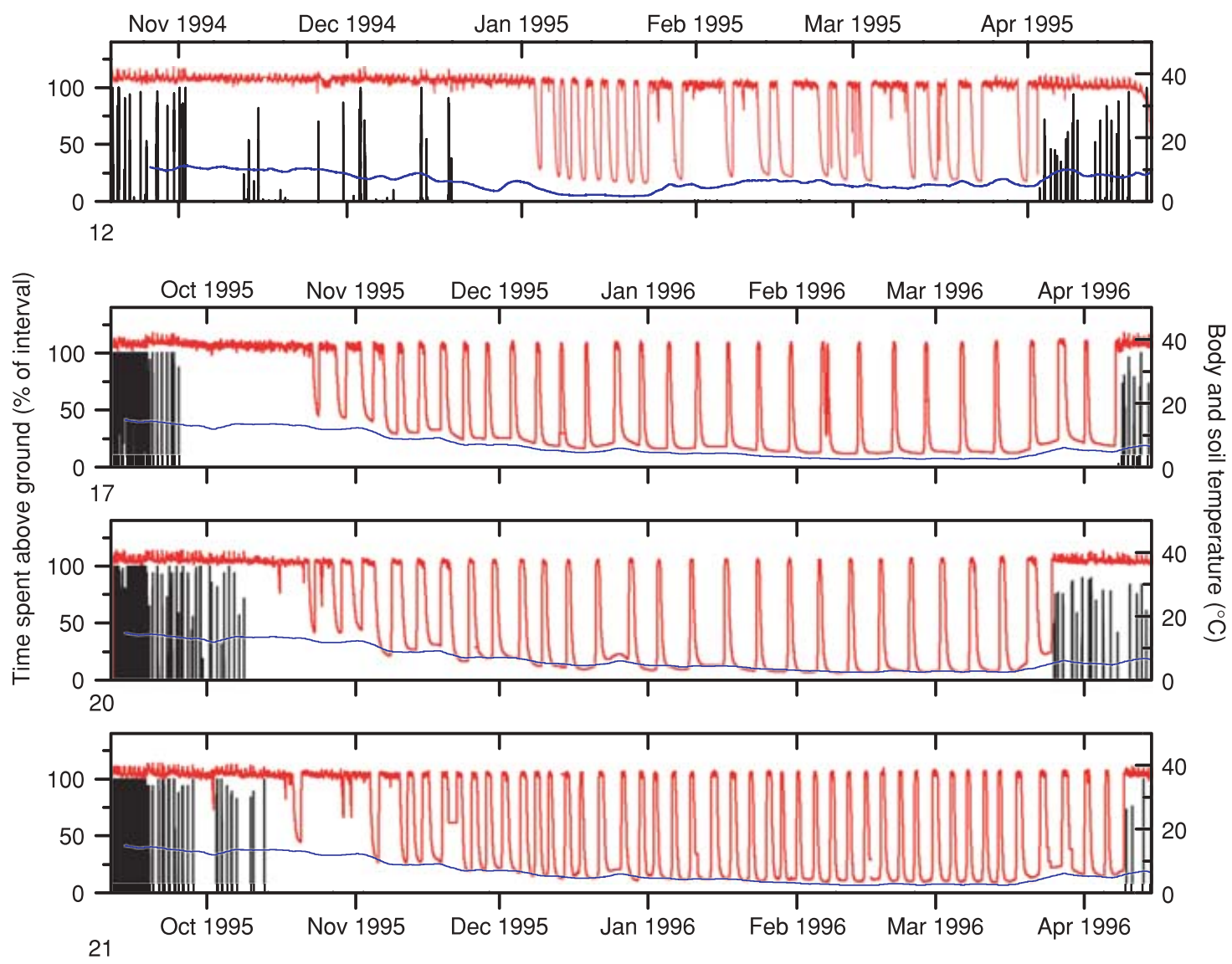

Fig. 2. Hibernation patterns of hamsters 12, 17, 20 and 21 as examples of a dense regular pattern of heterothermia with no time spent above-ground during winter (pattern type 1). Panels and axes as in Fig. 1. Recordings of hamster 21 showed some minor disturbances; when this happened the last reliable value was kept until reliable data could be recorded again.

of hibernation, normothermic $T_{\mathrm{b}}$ (normothermia, $\mathrm{Nt}$ ) fluctuates with the pattern of TAG. Please note that after an initial dense pattern of TAG, which correlates with the digging activity of the animal constructing its burrow, the pattern becomes less dense consisting of 2 major peaks of daily TAG during dusk and dawn (Fig. 1). In accordance with Michener (1992), the final retreat into the burrow (immergence) was defined as the onset of hibernation. Consequently, the period of hibernation was defined as the time hamsters continuously stay below ground. In Fig. 1, the hamster shown stays normothermic for almost 20 days before the first decline of $T_{\mathrm{b}}$ below normothermic values. This time period was referred to as 'postimmergence normothermia' (piNt). The following period of 'heterothermia' is characterized by discrete periods of hypothermia (hibernation bouts, HBs) interrupted by normothermic episodes (inter-bout normothermia, IBN) of short duration. HBs were defined as time between the drop of $T_{\mathrm{b}}$ below $30^{\circ} \mathrm{C}$ and the return to a $T_{\mathrm{b}}$ equal to or above $30^{\circ} \mathrm{C}$. The period of heterothermia ends after the rewarming from the last HB after which some animals leave their burrows almost immediately. This first TAG is called emergence and was defined as the end of hibernation (again following Michener, 1992). However, some animals stay underground for some time. This behaviour was called pre-emergence normothermia $(\mathrm{peNt})$.

\section{Statistical analyses}

During this investigation, $T_{\mathrm{b}}$ of hamsters, $T_{\mathrm{a}}$ (soil and above-ground temperature) and TAG were continuously monitored at a temporal resolution of $5 \mathrm{~min}$ over 48 months. All subsequent analyses were based on these 5-min values.

A computer program (Statistica, StatSoft Inc.) was used to compare data across animals and hibernation patterns. For parametrically distributed data, means \pm SD and repeated measures analyses of variance (ANOVA or MANOVA) were used, while for non-parametrically distributed data, medians $\pm 25 \%$ percentiles and KruskalWallis analyses of variance were used.

\section{RESULTS}

A total of 11 complete recordings could be used for the analyses of the patterns of body temperature and TAG (Table 1, Figs 2-4).

\section{Patterns of body temperature}

As in all hibernating species studied so far, hibernation of the European hamster is typically associated with discrete 

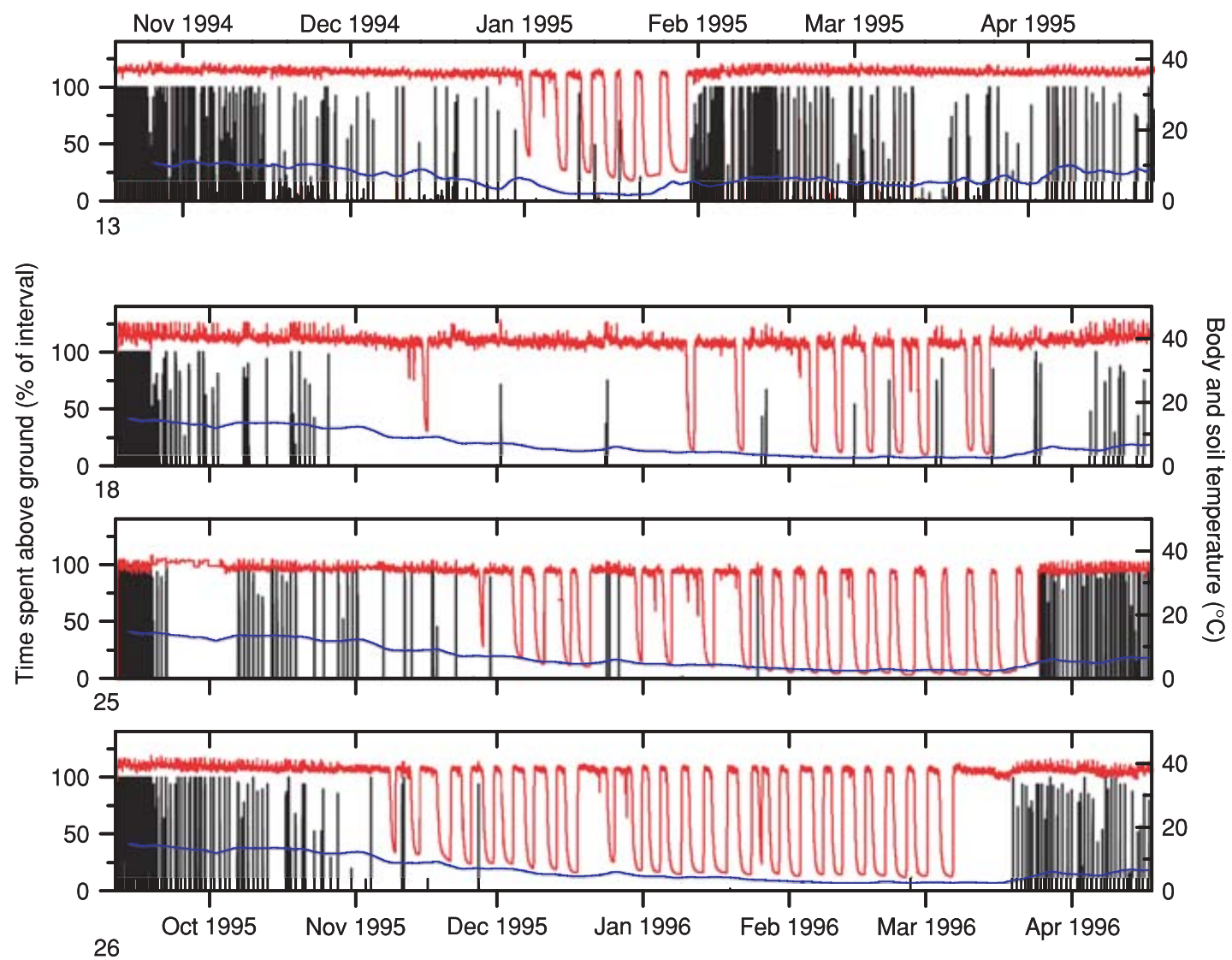

Fig. 3. Hibernation patterns of hamsters 13, 18, 25 and 26 showing a dense regular pattern of heterothermia with only little time spent above-ground (TAG) during winter (pattern type 2). Panels and axes as in Fig. 1. At the beginning of the recordings of hamster 25, the antenna in the bottom of the cage was not connected to the recording device. Detection of TAG was not reliable during this period and was excluded from the graph.

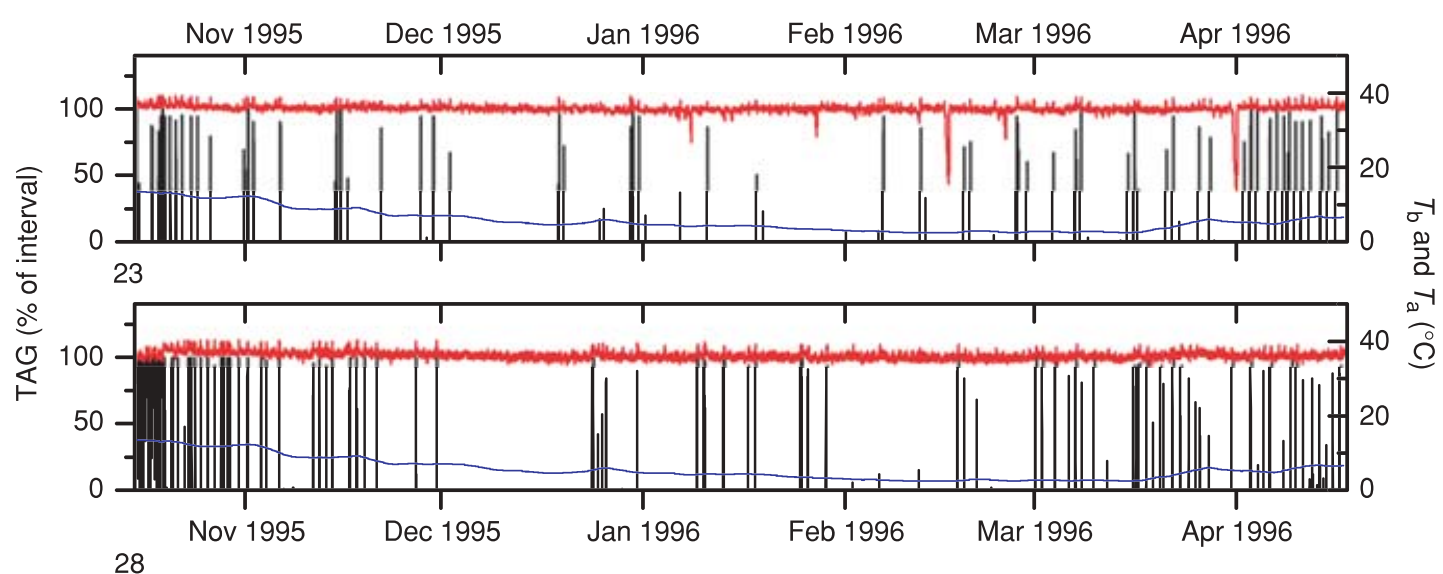

Fig. 4. Upper panel: hibernation of hamster 23 showing an irregular pattern of body temperature with frequent time spent above-ground (TAG) during winter (pattern type 3). Lower panel: hibernation of hamster 28 characterized by the absence of any hibernation bouts combined with frequent TAG during winter (pattern type 4). Panels and axes as in Fig. 1.

HBs, separated from each other by IBN (Fig. 1). Of 11 hamsters, nine showed a regular pattern of 7-44 HBs with a decline of $T_{\mathrm{b}}$ close to soil temperature (minimum $T_{\mathrm{b}}=0.97^{\circ} \mathrm{C}$ ) and durations of up to 6.9 days (Table 1 , Figs $2 \& 3$ ). One hamster showed only a few HBs separated from each other by long periods of IBN (hamster 23, Table 1, Fig. 4). Finally, hamster 28 did not show any HB at all (Table 1, Fig. 4).

The first HBs occurred between 2 October and 8 January, while the last heating-up from a HB ranged 
between 29 January and 9 April. Of the total duration of the hibernation season between $1.6 \%$ and $80.2 \%$ were spent in hypothermia $\left(T_{\mathrm{b}}\right.$ below $\left.30^{\circ} \mathrm{C}\right)$. Mean $T_{\mathrm{b}}$ during hibernation ranged between 13.46 and $37.47^{\circ} \mathrm{C}$. The longest HBs were observed between the end of December and the end of March.

\section{Above-ground patterns}

Hamsters stayed in their burrows for 1.4-28.1 days before the first decline of $T_{\mathrm{b}}$ below normothermic values (piNt; Fig. 1). After the final return to normothermia in spring, the animals remained inside their burrow for $0.5-12.7$ days (peNt, Fig. 1). There was a non-significant trend of female hamsters to show longer periods of piNt $(20.2 \pm 9.3$ vs $12.8 \pm 7.4$ days (median \pm 25 th percentile); $P<0.1$ median test, $\chi^{2}=2.7$, d.f. $=1$ ). No other sex-related trends were found within the TAG data (Table 1).

During hibernation, total TAG ranged between 0 and $16.1 \mathrm{~h}$. Although patterns of TAG during hibernation showed a wide individual variety, they could be subdivided into four main categories (Table 1, Figs 2-4).

Pattern 1: five animals showed a regular pattern of multiple HBs with only short periods of IBN. There was no TAG between autumnal immergence and emergence in spring (four examples shown in Fig. 2).

Pattern 2: four hamsters also showed a dense pattern of HBs interrupted by a few longer periods of IBN typically accompanied by short times of TAG (Fig. 3).

Pattern 3: only one animal expressed exclusively short and irregularly distributed HBs. Some of the prolonged periods of IBN were associated with significant times of TAG (hamster 23, Fig. 4).

Pattern 4: another hamster did not show any HBs at all. Nevertheless, the animal spent periods of $>3$ weeks continuously below ground (hamster 28 , Fig. 4). In addition, TAG during winter accounted for only about $13.6 \%$ of the same animal's normothermic values before and after winter. Mean $T_{\mathrm{b}}$ was significantly reduced between 20 November and 10 April, again compared to the animal's own normothermic values before and after this time $(36.00 \pm 0.75$ vs $36.36 \pm 0.62, t$-test for dependent samples $t(4178,4177)=10.9, P<0.0001)$.

The classification of complex hibernation patterns into four categories was first established by a qualitative comparison of the patterns of $T_{\mathrm{b}}$ and TAG among the animals (Table 1, Figs 2-4). They were later confirmed by running a one-way MANOVA on the effect of hibernation pattern type on the relative change of TAG (Rao's $R_{6,10}$ : 52.93, $P<0.0001)$.

\section{DISCUSSION}

Hibernation is commonly defined either by the time an animal stays continuously in its shelter, typically below ground (Michener, 1992), or by the time between the first major reduction of $T_{\mathrm{b}}$ until the final re-establishment of normal metabolism (Cabanac \& Simon, 1987; Barnes \&
Ritter, 1993; Hut, Barnes et al., 2002). The latter is also referred to as the 'heterothermal period' or heterothermia (Michener, 1992). Both periods could ideally be identical. However, in Richardson's ground squirrel Spermophilus richardsonii as in many other species, hibernation and heterothermia (sensu Michener, 1992) differ in regards to reproductive strategies. In the European hamster, both criteria are useful to define hibernation in pattern 1 and with limitations are also useful for pattern 2 (Table 1 , Figs $2 \& 3$ ). In contrast to this, both criteria, even a combination of both are completely insufficient for patterns 3 and 4 (Table 1, Fig. 4). Hamster 23 did not show any HB until 8 January (Fig. 4, upper panel). However, its pattern of TAG did show prolonged periods of continuous stays below ground before this time (e.g. 2 December until 18 December). A closer look at the $T_{\mathrm{b}}$ shows a change in mean temperature and amplitude beginning from the end of October, indicating some type of change in metabolism and behaviour.

The same is true for hamster 28 (Fig. 4, lower panel). Although this hamster did not show any HBs at all, the pattern of TAG as well as minor changes in the time course of $T_{\mathrm{b}}$ indicates some modification of metabolism and behaviour. From 30 November until 24 December and again from 29 January to 19 February, the hamster stayed continuously in its burrow. During these times the mean and amplitude of $T_{\mathrm{b}}$ were significantly reduced. Even during the whole winter (20 November until 10 April) mean $T_{\mathrm{b}}$ was significantly reduced (both periods compared to the corresponding values before and after winter). All these facts indicate a non-conventional 'hibernation' exhibited by this animal.

There was no indication or statistical evidence that animals showing hibernation patterns 3 or 4 were disturbed to develop a 'classical' pattern of type 1 or 2 . Likewise, there was no clue why some animals showed long latencies before their first hibernation bouts (hamsters 12, 13 and 18; Figs $3 \& 4$ ).

Only a few other investigations report the occurrence of TAG during hibernation in the European hamster so far. Gubbels, van Gelder \& Lenders (1989) examined the hibernation of a single European hamster under completely natural conditions. The animal showed $23 \mathrm{HBs}$ and stayed continuously below the ground. Weinhold (1998) conducted an extensive field study on the ecology of European hamsters. Immergence (plugging of burrow entrance) ranged between August and October, while emergence (opening of the burrow entrance) occurred between March and April. The state of the burrows was checked once a week. According to this method, none of 10 animals showed any TAG. Unfortunately, the method is not reliable to exclude TAG since hamsters are able to open and close their burrow quickly. However, as five out of 10 hamsters in our study did not show any TAG, and three more only moved above the ground briefly, TAG seems not to be common in European hamsters.

In contrast to the results for the European hamster, $66.9 \%$ of all arousals from HBs in the marsupial mountain pygmy-possum Burramys parvus were accompanied by 
TAG (Körtner \& Geiser, 1998). The corresponding value for the European hamster in this study is $20.1 \%$. Another important difference between the species is the synchronization of arousals from multi-day HBs in the Australian hibernator to the daily cycle of the environment. Thus, after multi-day $\mathrm{HBs}$, European hamsters leave their burrows at random times (pers. obs.), while Burramys return from hibernation just in time for an optimal foraging (Körtner \& Geiser, 1998). In the mountain pygmy-possum, TAG might be a regular and normal event, ensuring a sufficient energy supply for the continuation of hibernation.

Beginning in late summer, European hamsters hoard food and store it in their burrows (Nechay et al., 1977). As a result of this, they are not as dependent on a good food supply immediately before and during hibernation as may be the case for the Australian hibernator. European hamsters can therefore afford to reduce or postpone TAG during winter and do not need a mechanism to stay synchronized to the environmental cycle of day and night.

Torke \& Twente (1977) studied the time budget spent on different activities during IBN in the ground squirrel Spermophilus lateralis in the laboratory. Exploratory behaviour and feeding, which involves leaving the hibernacula, accounted for $<1.5 \%$ of the time. In the present study, TAG during IBN in the European hamster accounted for $0-0.8 \%$, median $0.1 \%$ of total time in IBN. It was not possible to determine the kind of activity European hamsters showed while in IBN. Due to weekly controls and, if necessary, refilling of food racks, it can be concluded that only in a few cases, these journeys above the ground were taken in order to gather food.

Major locomotor activity during IBN, accompanied with a temporary leave or even switching between hibernacula, seems to be a regular event in the mountain pygmypossum (Körtner \& Geiser, 1998) and some Gliridae species (Vogel \& Frey, 1995; Vogel, 1997). In contrast to this, other species like European hamsters, ground squirrels and marmots do not interrupt hibernation in this way (this study; Young, 1990; Michener, 1992; Arnold, 1993). These species typically stay constantly in their burrows. In nature, it is most probably only the starving animal, which has used up its energy savings in food storage or body fat, that moves above ground in the desperate attempt to find food. Most of these animals will not survive the winter.

Hibernating animals are believed to stay continuously in their hibernacula and express a dense pattern of HBs. The occurrence of dissociated patterns of body temperature reduction and TAG in some of the European hamsters in this study made it extremely difficult to define the beginning and end of hibernation in these animals. Hence, the hibernating behaviour of the European hamster seems to be different from other species. However, exact studies focusing on the patterns of $T_{\mathrm{b}}$ and TAG are missing in most other hibernating species. Therefore, it cannot be excluded that the classical concept of hibernation is only one and may not even be the most common pattern in a highly variable mechanism.

\section{Acknowledgements}

Thanks to Franziska Wollnik from the University of Stuttgart for guiding me into chronobiology and to the staff of the Technical Workshop of the University of Konstanz for their excellent work and support. This study was funded by a grant of the Deutsche Forschungsgemeinschaft (Wo 354/5-2).

\section{REFERENCES}

Arnold, W. (1993). Energetics of social hibernation. In Life in the cold. Ecological, physiological and molecular mechanisms: 65 80. Carey, C., Florant, G. L., Wunder, B. A. \& Horwitz, B. (Eds). Boulder, CO: Westview Press.

Barnes, B. M. \& Ritter, D. (1993). Patterns of body temperature change in hibernating arctic ground squirrels. In Life in the cold. Ecological, physiological and molecular mechanisms: 119-130. Carey, C., Florant, G. L., Wunder, B. A. \& Horwitz, B. (Eds). Boulder, CO: Westview Press.

Cabanac, M. \& Simon, E. (1987). Glossary of terms for thermal physiology. Pflueg. Arch. Eur. J. Physiol. 410: 567-587.

Dubois, R. (1896). Physiologie comparée de la Marmotte. Paris: Masson.

Eisentraut, M. (1928). Über die Baue und den Winterschlaf des Hamsters (Cricetus cricetus L.). Z. Säugetierkd. 3: 172208.

Grulich, I. (1986). The reproduction of Cricetus cricetus (Rodentia) in Czechoslovakia. Acta Sci. Nat. Acad. Sci. Bohemoslov. Brno (N. S.) 20: 1-56.

Gubbels, R. E. M. B., van Gelder, J. J. \& Lenders, A. (1989). Thermotelemetric study on the hibernation of the common hamster, Cricetus cricetus (Linnaeus, 1758), under natural circumstances. Bijdr. Dierkd. 59: 27-31.

Heldmaier, G., Klaus, S. \& Wiesinger, H. (1990). Seasonal adaptation of thermoregulatory heat production in small mammals. In Thermoreception and temperature regulation: 235 243. Bligh, J. \& Voigt, K. (Eds). Berlin: Springer-Verlag.

Hut, R. A., Barnes, B. M. \& Daan, S. (2002). Body temperature patterns before, during, and after semi-natural hibernation in the European ground squirrel. J. comp. Physiol. B biochem. syst. environ. Physiol. 172: 47-58.

Hut, R. A., van Oort, B. E. H. \& Daan, S. (1999). Natural entrainment without dawn and dusk: the case of the European ground squirrel (Spermophilus citellus). J. biol. Rhythms 14: 290-299.

Körtner, G. \& Geiser, F. (1998). Ecology of natural hibernation in the marsupial mountain pygmy-possum (Burramys parvus). Oecologia (Berl.) 113: 170-178.

Michener, G. R. (1992). Sexual differences in over-winter torpor patterns of Richardson's ground squirrels in natural hibernacula. Oecologia (Berl.) 89: 397-406.

Nechay, G., Hamar, M. \& Grulich, I. (1977). The common hamster (Cricetus cricetus [L.]); a review. Eur. Mediterr. Plant Prot. Organ. Bull. 7: 255-276.

Niethammer, J. (1982). Cricetus cricetus (Linnaeus, 1758) hamster (Feldhamster). In Handbuch der Säugetiere Europas 2/1 Rodentia: 7-28. Niethammer, J. (Ed.). Wiesbaden: Akademische Verlagsgesellschaft.

Petzsch, H. (1936). Beiträge zur Biologie, insbesondere Fortpflanzungsbiologie des Hamsters (Cricetus cricetus L.) Ergebnisse und Probleme. Z. Kleintier Pelztierkd. 1: 1-83.

Petzsch, H. (1952). Der Hamster. Leipzig: Akademische Verlagsgesellschaft Geest \& Portig K.-G.

Sulzer, F. G. (1774). Versuch einer Naturgeschichte des Hamsters. Göttingen \& Gotha. 
Torke, K. G. \& Twente, J. W. (1977). Behavior of Spermophilus lateralis between periods of hibernation. J. Mammal. 58: 385-390.

Vogel, P. (1997). Hibernation of recently captured Muscardinus, Eliomys and Myoxus: a comparative study. Nat. Croat. 6: 217-231.

Vogel, P. \& Frey, H. (1995). L'hibernation du muscardin Muscardinus avellanarius (Gliridae, Rodentia) en nature: nids, fréquence des réveils et température corporelle. Bull. Soc. Vaudoise Sci. Nat. 83(3): 217-230.

Vohralik, V. (1975). Postnatal development of the common hamster Cricetus cricetus (L.) in captivity. Rozpr. Cesk. Akad. Ved Rada Mat. Prir. Ved (Prag) 9: 1-48.

Wassmer, T. (1998). Die zeitliche Organisation des Winterschlafs beim Europäischen Feldhamster (Cricetus cricetus L.). München: Herbert Utz Verlag Wissenschaft.
Weinhold, U. (1998). Zur Verbreitung und Ökologie des Feldhamsters (Cricetus cricetus L 1758) in Baden-Württemberg, unter besonderer Berücksichtigung der räumlichen Organisation auf intensiv genutzten landwirtschaftlichen Flächen im Raum Mannheim-Heidelberg. 130. Thesis, Ruprecht-Karls Universität Heidelberg.

Wollnik, F. \& Schmidt, B. (1995). Seasonal and daily rhythms of body temperature in the European hamster (Cricetus cricetus) under semi-natural conditions. J. comp. Physiol. B biochem. syst. environ. Physiol. 165: 171182.

Young, P. J. (1990). Hibernating patterns of free-ranging Columbian ground squirrels. Oecologia (Berl.) 83: 504511. 